\title{
The late presentation of postero-lateral congenital diaphragmatic hernias
}

\author{
N.D. Heaton, G. Adam and E.R. Howard \\ Department of Surgery, King's College Hospital, Denmark Hill, London SE5 9RS, UK
}

Summary: Four patients presenting after the neonatal period with a combination of respiratory and gastro-intestinal symptoms and signs which point to the diagnosis of congenital postero-lateral diaphragmatic hernias are discussed. Late presentation is more common than previously acknowledged. Early correct diagnosis and treatment are associated with an excellent clinical outcome.

\section{Introduction}

Lazarus Riverius first described a congenital diaphragmatic hernia $(\mathrm{CDH})$ in 1690 found incidentally in a 24 year old man at postmortem, ${ }^{1}$ but it was not until the beginning of this century that successful surgical treatment of $\mathrm{CDH}$ was pioneered. Despite the initial description in an adult, most patients with postero-lateral $\mathrm{CDH}$ present acutely in the neonatal period, and late presentation has been considered rare, although an increasing number of recent publications suggest otherwise. Estimates of the proportion of patients presenting late vary from $5 \%^{2}$ to $25 \%$. $^{3,4}$

The postero-lateral hernia results from a defect in the pleuro-peritoneal canal with subsequent herniation of abdominal contents (in utero). There is associated pulmonary hypoplasia, the severity of which determines the time of presentation and the likelihood of survival. Patients presenting late appear to have mild pulmonary hypoplasia and the prognosis following surgical correction is correspondingly excellent. The prompt diagnosis of late presentation of $\mathrm{CDH}$ will reduce surgical morbidity and mortality. Four patients presenting with congenital postero-lateral $\mathrm{CDH}$ are reported.

\section{Patients}

\section{Patient 1}

A full-term $2.5 \mathrm{~kg}$ male infant developed breathing problems shortly after birth and a chest X-ray (Figure la) at the time was normal. His symptoms settled and he remained well for 10 weeks when he developed vomiting and diarrhoea. On examina-

a

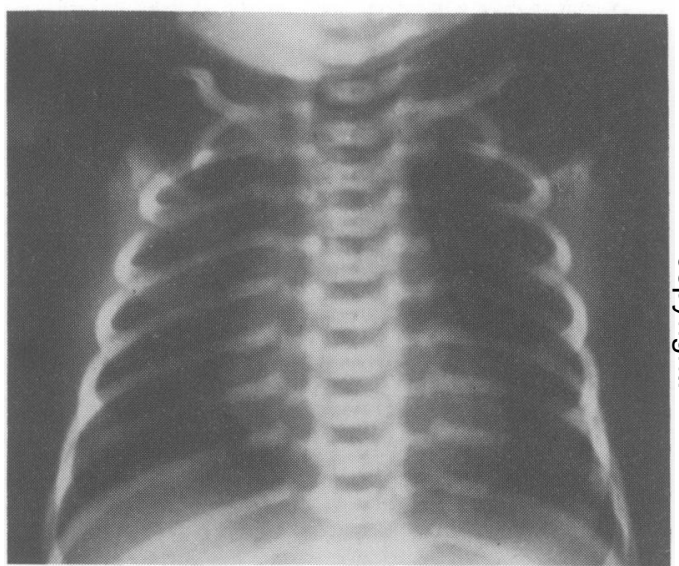

b

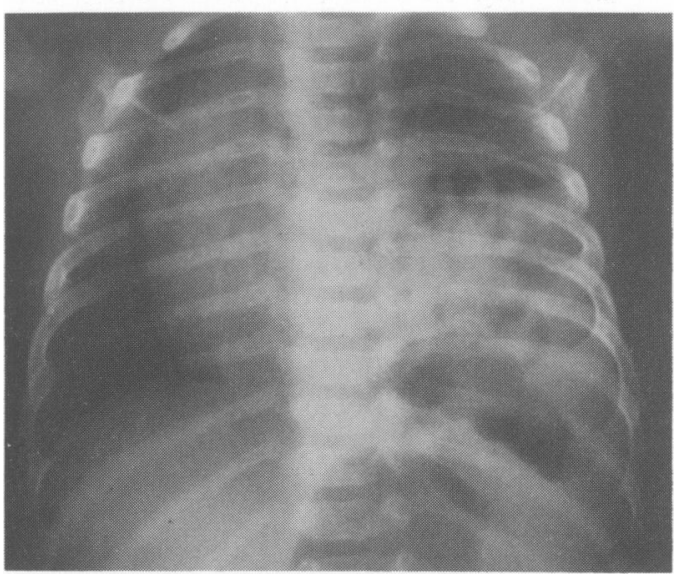

Figure 1 Case 1. (a) Normal chest X-ray shortly after birth. (b) Plain chest X-ray at 10 weeks. The left chest is filled with loops of bowel, and the mediastinum is shifted to the right. 
tion bowel sounds were heard in the chest. Loops of small and large bowel were seen in the left chest on $\mathrm{X}$-ray (Figure 1b). At laparotomy there was a large left $\mathrm{CDH}$ which contained small bowel, transverse colon, left adrenal gland, spleen and there was no peritoneal sac present. There was an associated malrotation of the bowel with a Ladd's band. The hernia was reduced, the diaphragm repaired and Ladd's procedure with appendicectomy performed. The patient made an uneventful recovery.

\section{Patient 2}

A previously well 1 year old girl presented with a 6 hour history of abdominal pain, but no vomiting or alteration of bowel habit. The child had some difficulty with respiration, but had no cough or coryza. On examination the child was apyrexial and dehydrated, with a tachycardia, tachypnoea and an expiratory grunt. The trachea was deviated to the right and breath sounds were absent in the left lower chest. The abdomen was tender to palpation and bowel sounds were quiet.. Shortly after this the child became cyanosed. It was initially thought she had developed a tension pneumothorax (Figure 2a), but the passage of a nasogastric tube provided immediate symptomatic relief; a further chest X-ray (Figure 2b) confirmed that the stomach had herniated into the chest. At laparotomy there was a $4 \mathrm{~cm}$ defect in the posterolateral diaphragm containing a peritoneal sac with the greater curvature of the stomach and the spleen. Following reduction of the hernial contents the sac was excised and the defect closed by direct suture. Postoperatively there were no complications.

\section{Patient 3}

A 2 year old boy presented with sudden onset of colicky abdominal pain and profuse vomiting. On examination he was unwell, tachycardic and was dull to percussion over the left lower chest; bowel sounds were heard over this area. Abdominal examination was unremarkable. The left hemidiaphragm was elevated on a plain abdominal $\mathrm{X}$-ray. A chest $\mathrm{X}$-ray, barium meal and enema confirmed the presence of small and large bowel lying in the chest (Figure 3). At operation a $5 \mathrm{~cm}$ defect in the posterior aspect of the left diaphragm was repaired by direct suture after reduction of the small and large bowel. There was no associated peritoneal sac. The patient was discharged home 10 days postoperatively.

\section{Patient 4}

A 19 year old student presented with a 4 day history of sharp constant pain in the left chest and a

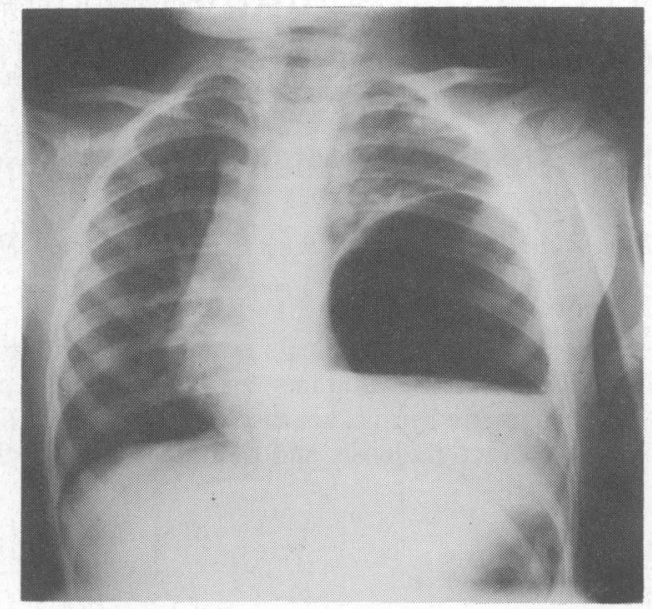

b

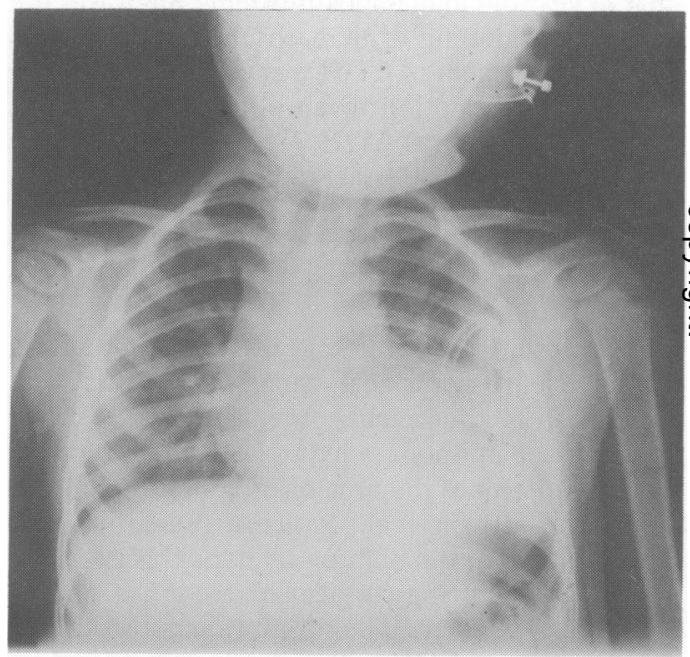

Figure 2 Case 2. (a) Plain chest X-ray. Distended intrathoracic stomach compressing the left lung. (b) Plain chest X-ray. Passage of the nasogastric tube has decompressed the stomach.

abdomen; he had experienced seven similar, but milder episodes lasting 2-3 days during the previous 2 years. The pain was aggravated by deep inspiration, and relieved by lying on his right side, or with his head between his knees. He also complained of nausea, without vomiting, intermittent dysphagia at the level of the clavicles, and postprandial indigestion. He had also developed breathlessness, palpitations, and sweating on mild exertion. Apart from pneumonia as a child, there was no history of injury or trauma. A chest X-ray 2 


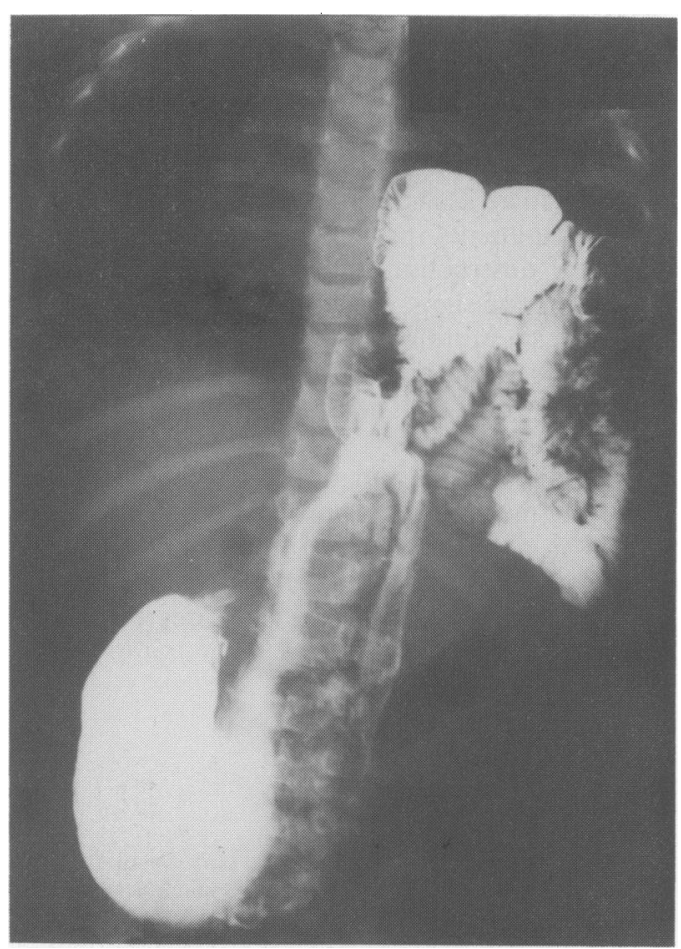

Figure 3 Case 3. Barium meal and follow-through. Small bowel present in the chest.

years previously was normal. Clinical examination was reported normal and he was discharged with antacids. He returned the next day with similar symptoms, but on examination was found to have a tachycardia, the trachea and apex beat were displaced to the right and the left chest was dull to percussion with reduced breath sounds. Abdominal examination was normal. Loops of small bowel were seen in the left chest on the subsequent chest X-ray. A barium meal and follow-through showed no evidence of a malrotation. At emergency left thoracotomy, the chest was filled by a tense dilated stomach, spleen, and transverse colon, passing through a posterolateral hernia. The contents were reduced after a decompression gastrotomy and the defect was directly sutured. A chest drain was inserted prior to closure. The patient was discharged on the 10th postoperative day.

\section{Discussion}

The diaphragm forms from the septum transversum which grows downwards and backwards to meet the dorsal mesentery of the foregut. ${ }^{5}$ Pleuroperitoneal folds then develop on each side of the septum and extend postero-laterally dividing the chest from the abdomen. A small triangular posterior portion, the pleuro-peritoneal canal is the last area to close. The diaphragm is completed at the ninth week by an ingrowth of muscle fibres from cervical myotomes into the pleural and peritoneal folds. This coincides with the return of intestine from the umbilical stalk. Delayed closure of the diaphragm (the left is normally a week later in closing than the right), or early return of intestine to the abdomen may result in a hernia. If this happens before the pleuro-peritoneal canal closes the hernia has no associated peritoneal sac, but if later in the embryological sequence, after canal closure and before muscle ingrowth is completed, a sac will be present. Left-sided hernias are more common than right because of the later closure of the pleuro-peritoneal canal and the protective effect of the liver.

The late presentation of postero-lateral $\mathrm{CDH}$ was considered rare, but an increasing number of publications indicate that up to a quarter of patients are diagnosed after the neonatal period. Patients present with a wide variety of gastrointestinal and respiratory symptoms, but at least a quarter will be asymptomatic, ${ }^{6}$ and are often diagnosed incidentally on a chest X-ray. ${ }^{7}$ Kirkland ${ }^{8}$ characterized the symptoms of late presentation as 'grumbling, remittant and misleading', and thought that the 'free movement of abdominalo viscera between the pleural and peritoneal cavitieso was responsible for the protean character of symp-? toms'.

Free movement of bowel between pleural and peritoneal cavities may explain why many patients presenting late with a postero-lateral $\mathrm{CDH}$ have had a previously normal chest X-ray, ${ }^{9-15}$ and our first patient was an example of this presentation. A normal chest $\mathrm{X}$-ray and barium series do not exclude a congenital diaphragmatic hernia. Symptoms may be intermittent ${ }^{16}$ and mechanical factors, including large meals, ${ }^{17}$ postoperative ileus, ileal loop construction, ${ }^{15}$ gastro-enteritis, trauma, obesity, pregnancy and physical exertion, ${ }^{17}$ which either raise intra-abdominal pressure or cause acute distension of abdominal viscera, may precipitate herniation and the onset of symptoms. The three older patients presented acutely with combination of respiratory and gastro-intestinal symptoms and signs. This association points strongly to the diagnosis of $\mathrm{CDH}^{2,18,19}$

Acute presentation is usually due to incarceration, obstruction, or strangulation of the hernia. A resulting gastric volvulus may cause partial or complete obstruction, strangulation, or ulceration with bleeding or perforation. Case 2 developed rapid and severe respiratory embarrassment from an acutely distended stomach and immediate symptomatic relief was provided by the passage of a naso-gastric tube. The small and large bowel are 
the commonest structures to herniate, but the stomach is present in about $40 \%$ of hernias, and hernias involving the liver, spleen, pancreas, adrenal gland and kidney have all been described.

The incidence of malrotation in the newborn with CDH is approximately $30 \%{ }^{20}$ and was initially considered to be rare in late presentation. However, it appears to be present in about one third of these patients. Only one of our four cases had a malrotation with an associated Ladd's band. Malrotation can be diagnosed preoperatively by barium meal (to identify duodenal position) and enema (to identify caecal position), if the patient is not acutely ill. An abdominal incision is the recommended approach for all age groups. One adult patient in this small series had a thoracic incision, but this approach has not been recommended because of the association of diaphragmatic hernia and intestinal malrotation. An abdominal incision allows for the operative recog- nition and treatment of malrotation and avoids the bowel being returned from the chest with a volvulus due to abnormal small or large bowel fixation.

In all our patients the diaphragmatic defect was small and repaired by direct suture and only one patient had an associated peritoneal sac. Although all four patients presented with symptoms of intestinal obstruction with associated respiratory symptoms and signs, none had strangulated. Strangulation is a more common complication of traumatic $(90 \%)$ diaphragmatic hernias ${ }^{21}$ and when it does occur in CDH it is usually because of delayed or missed diagnosis ${ }^{13}$ which is associated with increased morbidity and mortality. Early diagnosis and treatment after appropriate investigations results in a low incidence of morbidity and no mortality. The long-term results are excellent as few patients have any significant degree of pulmonary hypoplasia.

\section{References}

1. Ravitch, M.M. Congenital diaphragmatic hernia. In: Nyhus, L.M. \& Harkins, H.N. (ed.) Hernia. Pitman Medical Publishing, London, 1962, pp. 527-545.

2. Osebold, W.R. \& Soper, R.T. Congenital posterolateral diaphragmatic hernia past infancy. Am J Surg 1976, 131: 748-754.

3. Newman, B.M., Afshani, E., Karp, M.P., Jewett, T.C. \& Cooney, D.R. Presentation of congenital diaphragmatic hernia past the neonatal period. Arch Surg 1986, 121: 813-816.

4. Synder, W.H. \& Greaney, E.M. Congenital diaphragmatic hernia; 77 consecutive cases. Surgery 1965, 57: 576-588.

5. Kissane, J.M. \& Smith, M.G. Posterolateral diaphragmatic hernia. In: Pathology of Infancy and Childhood. C.V. Mosby, St Louis, 1967, pp. 508-509.

6. Ahrend, T.R. \& Thompson, B.W. Hernia of the foramen of Bochdalek in the adult. Am J Surg 1971, 122: 612-615.

7. Ketonen, P., Mattila, S.P., Harjola, P.T., Jarvinen, A. \& Mattila, T. Congenital posterolateral diaphragmatic hernia in the adult. Acta Chir Scand 1975, 141: 628-632.

8. Kirkland, J.A. Congenital posterolateral diaphragmatic hernia in the adult. $B r J$ Surg 1959, 47: 16-22.

9. Canino, C.W.M., Eichman, J., Rominger, C.J. \& Ryan, J.J. Congenital right diaphragmatic hernia. Radiology 1964, 82: 249-253.

10. Forshall, I. Less common herniae through the diaphragm of infants and children. Proc $R$ Soc Med 1966, 59: 212-214.

11. Kirchner, S.G., Burko, H., O'Neill, J.A. \& Stahlman, M. Delayed radiographic presentation of congenital right diaphragmatic hernia. Radiology 1975, 115: 155.
12. Hurdiss, L.W., Taybi, H. \& Johnson, L.M. Delayed appearance of left-sided diaphragmatic hernia in infancy. $J$ Pediatrics 1976, 88: 990-992.

13. Woolley, M.M. Delayed appearance of a left postero-lateral diaphragmatic hernia resulting in significant small bowel necrosis. J Pediatr Surg 1977, 12: 673-674.

14. Wiseman, N.E. \& MacPherson, R.I. 'Acquired' congenital diaphragmatic hernia. J Pediatr Surg 1977, 12: 657-665.

15. Day, B. Later appearance of Bochdalek hernia. Br Med J 1972, 1: 786.

16. Hight, D.W., Hixson, S.D., Reed, J.O., Watts, F.B. \& Hertzler, J.H. Intermittent diaphragmatic hernia of Bochdalek: Report of case and literature review. Pediatrics 1982, 69, 601-604.

17. MacDonald, J.T., Abbot, A.C. \& Goodhand, T.M. Herniation through congenital diaphragmatic defects in adults. Can J Surg 1963, 6: 301-316.

18. Lynch, J.M., Adkins, J.C. \& Wiener, E.S. Incarcerated congenital diaphragmatic hernias with bowel obstruction (Bochdalek). J Pediatr Surg 1982, 17: 537-540.

19. McCue, J., Ball, A., Brereton, R.J., Wright, V.M. \& Shaw, D. Congenital diaphragmatic hernia in older children. $J \boldsymbol{R}$ Coll Surg Edinb 1985, 30: 305-310.

20. Kiesewetter, W.B., Gutierrez, I.Z. \& Sieber, W.K. Diaphragmatic hernia in infants under one year of age. Arch Surg 1961, 83: $561-572$.

21. Cohen, D. \& Reid, I.S. Recurrent diaphragmatic hernia. $J$ Pediatr Surg 1981, 16: 42-44. 